\title{
Histopathological spectrum of disorders of sexual development: a case series of seven cases
}

\author{
Saroj Ashok Bolde, Arva Ali Pirosha*, Sushma N. Ramraje, Shubhangi V. Agale
}

Department of Pathology, Grant Government Medical College, Mumbai, Maharashtra, India

Received: 08 March 2020

Accepted: 30 April 2020

\section{*Correspondence:}

Dr. Arva Ali Pirosha,

E-mail: arvapirosha@gmail.com

Copyright: (C) the author(s), publisher and licensee Medip Academy. This is an open-access article distributed under the terms of the Creative Commons Attribution Non-Commercial License, which permits unrestricted non-commercial use, distribution, and reproduction in any medium, provided the original work is properly cited.

\begin{abstract}
Disorders of sexual development (DSD) refer to cases in which there is a discordance among at least two of the following; genetic sex, gonadal sex, genital tract sex and phenotypic sex. DSDs are quite rare with reported incidence varying from 1 in 4,500 to 1 in 5,500. Ovotesticular disorder is amongst the rarest variety of DSD comprising only to $3-10 \%$ of all cases of DSD with only 500 cases reported till now worldwide. Frequency of MRKH syndrome is 1 in 4,500 cases and is the cause of amenorrhoea in $15 \%$ of cases of primary amenorrhoea. Authors present a case series of seven cases of DSDs with three cases diagnosed as androgen insensitivity syndrome, two cases of true ovotesticular DSD (true hermaphrodite), one case each of mixed gonadal dysgenesis and Mayer-Rokitansky-Kuster Hauser (MRKH) syndrome. Authors received the histopathology specimen of these cases in this department which was extensively sampled to study the gonads and the other derivatives of Mullerian and Wolffian duct and to rule out presence of any malignancy.
\end{abstract}

Keywords: Androgen insensitivity, Disorder of sexual development, Hermaphrodite, Mixed gonadal dysgenesis, Ovotestis

\section{INTRODUCTION}

Chicago consensus 2005 established a revised nomenclature with the newly defined term as disorders of sexual development (DSD) replacing terms such as intersex, hermaphroditism and pseudo hermaphroditism as a group of congenital conditions with atypical development of chromosomal, gonadal or anatomic sex and external genitalia. ${ }^{1,2}$

Worldwide incidence of genital ambuiguity is 1:2000$1: 4500 .^{2,3}$

Classification of DSDs has been done in a variety of ways based on sex chromosome, androgen receptor defect, external phenotypes, defects in testosterone and dihydrotestosterone synthesis. Major types of DSDs are as follows. ${ }^{4}$

\section{Male pseudohermaphroditism}

Karyotype is $\mathrm{XY}$, gonads are testis and the phenotype is ambiguous or female.

\section{Persistent mullerian duct syndrome}

External phenotype is male with bilateral or unilateral cryptorchidism, normal Wolffian duct derivatives and a uterus usually with two fallopian tube within an inguinal hernia.

Defects in adrenal cortical hormone synthesis associated with congenital adrenal hyperplasia

Five enzymatic defects involving 20,22-desmolase,3betahydroxysteroid dehydrogenase, 17-betahydroxylase, 17,20 desmolase and 17-betahydroxysteroid 
dehydrogenase may cause male pseudohermaphroditism. Genetically males have cryptorchidism, variably developed Wolffian duct systems, absent Mullerian duct derivatives and female or ambiguous external genitalia.

\section{Androgen insensitivity syndrome}

Complete androgen insensitivity syndrome (AIS), also known as testicular feminization, is the most frequent cause of male pseudohermaphroditism. The etiological defect is the lack of androgen receptor (AR), because of which $\mathrm{T}$ and DHT are unable to affect the developing Wolffian duct system and external genitalia. Patients are usually phenotypically female with tall stature, wellformed breasts, absent or scanty axillary and pubic hair and a shallow vagina. The patient also has bilateral cryptorchidism with intra-abdominal, inguinal or labial testes and often has absent Wolffian and Mullerian duct derivatives. The microscopic appearance of testis is characteristic-spermatogonia is usually sparse, marked leydig cell hyperplasia may be seen and seminiferous tubules are usually small and may show immature sertoli cells.

\section{Gonadal dysgenesis}

It consists of a spectrum of disorders with ambiguous genitalia, persistent Mullerian duct structures, Wolffian duct structures, karyotyping having a Y chromosome and the potential for development of a neoplasm. It includes mixed gonadal dysgenesis (MGD), pure gonadal dysgenesis (PGD) and dysgenetic male pseudohermaphroditism (DMPH). MGD includes a testis or a gonadal tumour on one side and a rudimentary streak gonad or no gonad on the other side. A streak gonad consists of wavy ovarian type stroma with primordian ovarian follicle without ovum. External genitalia may be normal or ambiguous. The 45XO/46XY mosaic karyotype is most common. PGD includes bilateral streak gonads with persistent Mullerian structures and dysgenetic male pseudohermaphrodite includes bilateral dysgenetic testes with persistent Mullerian structures.

\section{True hermaphroditism}

In this case both ovarian and testicular tissue is found in the same patient either as bilateral ovotestes, as an ovotestis on one side and contralateral ovary or testis or as an ovary and contralateral testis.

\section{Female pseudohermaphrodite}

In this case individual has but external genitalia with secondary sexual characters are that of a male.

\section{CASE SERIES}

The histopathological specimen of all clinically diagnosed cases of DSD received in this tertiary care hospital in a period of six months were included. All the specimens were extensively sampled and representative sections taken and stained with haematoxylin and eosin stain. The gonads were sectioned and submitted fully to rule out any dysplastic or malignant changes. Complete clinical records of the patient with physical examination, radiological examination, blood hormonal investigations, karyotyping and other blood investigations were noted and evaluated to reach the final diagnosis in accordance with microscopic findings in each case.

\section{Case 1}

One-year old child, phenotypically male presented with left sided inguinal swelling. On examination patient had scrotal hypospadias with cordee, phallus measuring $2 \mathrm{~cm}$, right testis descended but left side testis palpable in inguinal region with left scrotum hypoplastic. On ultrasound examination uterus measuring $1.3 \times 0.5 \times 0.5 \mathrm{~cm}$ was noted. Ovaries were not seen. Karyotyping examination revealed presence of $46 \mathrm{XY}$. Patient underwent exploratory laprotomy with excision of uterus and left gonad followed by urethroplasty. Histopathological examination of the specimen received revealed ovarian stroma with primordian follicles (Figure 1). Fallopian tube was noted. Endometrial glands and endometrial stroma were also seen. In addition to this epidydimis and rete testis were also noted, thus this patient was diagnosed as a case of ovotesticular DSD (true hermaphrodite).

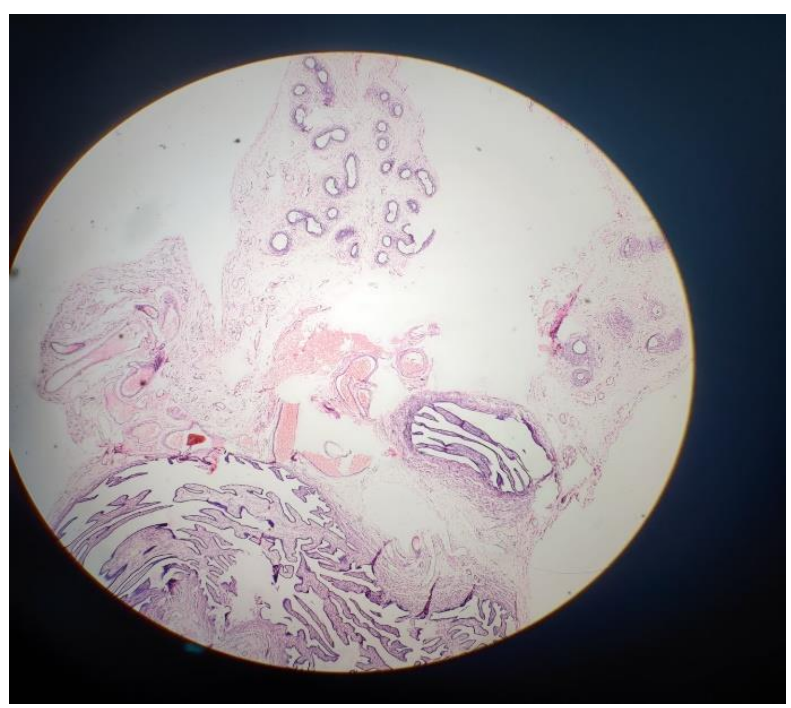

Figure 1: Testicular tissue, fallopian tube and ovarian tissue in case of true hermaphrodite ( $H$ and $E$ : $20 x)$.

\section{Case 2}

Thirteen-year-old male presented with abdominal pain and cyclical haematuria. On examination he had ambiguous external genitalia with a phallus. On ultrasound examination patient had a hypoplastic uterus with a blind elongated cervical canal and lower end of the vagina opened up into urerthra. Right side testis was descended but on left side patient had inguinal hernia. 
Subsequently total hysterectomy along with excision of left inguinal swelling was performed (Figure 2). Grossly the left sided inguinal mass was solid cystic (Figure 3 ).

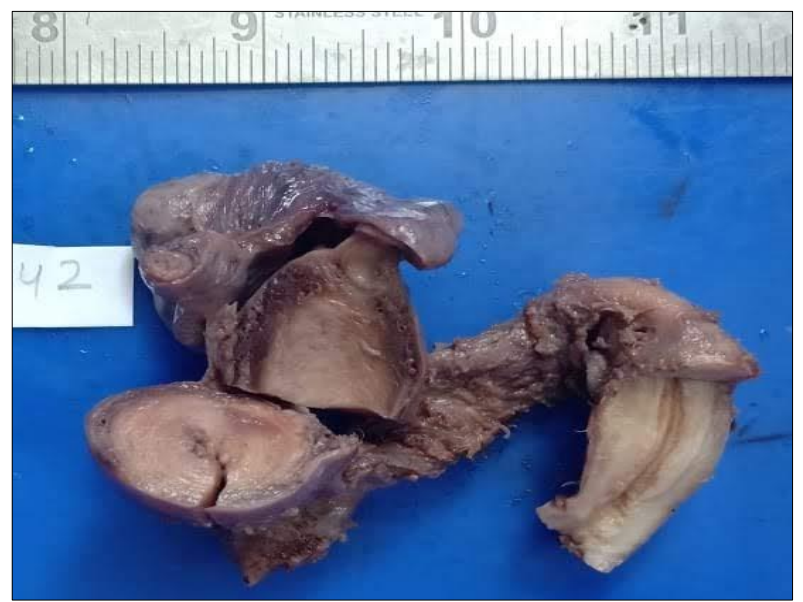

Figure 2: Gross-Elongated cervix with uterus and right ovary in case of true hermaphrodite.

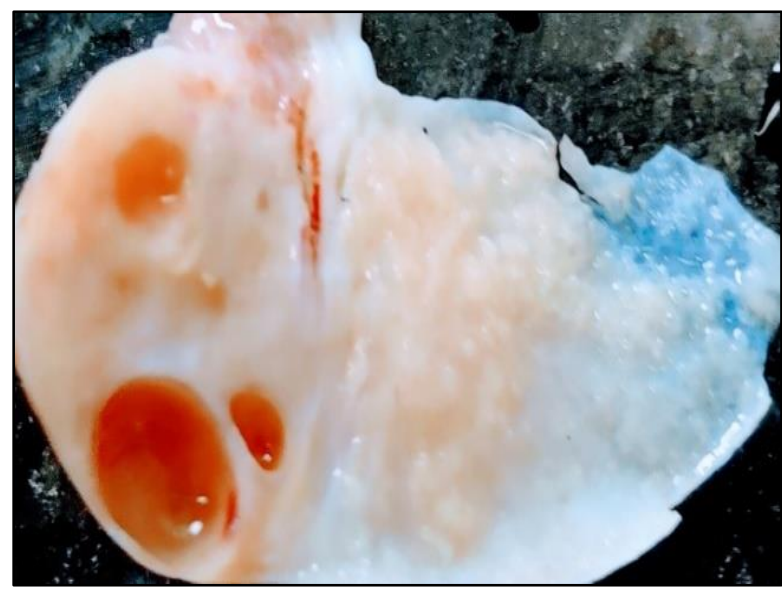

Figure 3: Gross-cut surface of left gonad, solid cystic grayish white in case of true hermaphrodite.

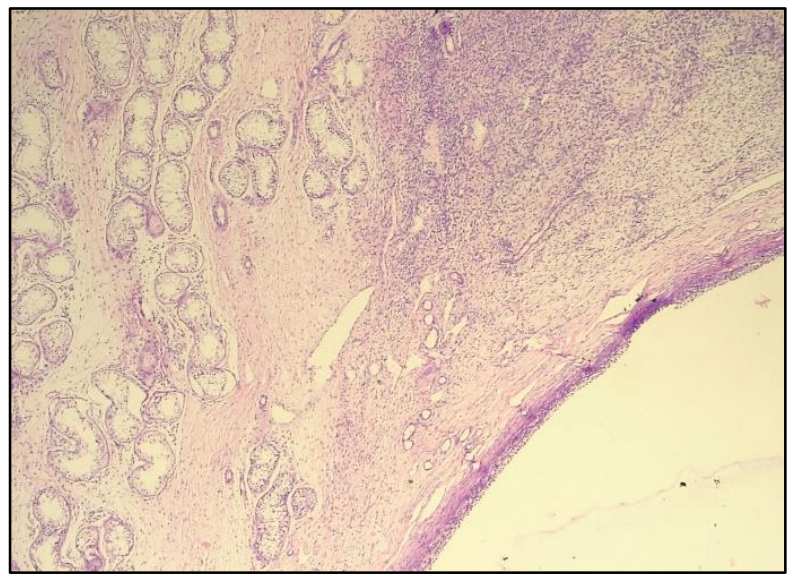

Figure 4: Ovotestis in case of true hermaphrodite (H and E: 20x).
On histopathological examination normal histology of uterus, cervix and vagina was identified along with identification of ovotestis in the section from left inguinal swelling (Figure 4). Thus the case was labelled as ovotesticular DSD (true hermaphrodite).

\section{Case 3, 4 and 5}

Two cases each of age eleven year old female and one case of thirteen year old female presented with bilateral inguinal swellings and ambiguous external genitalia. Karyotyping was done in only one case which showed 46XY chromosomes. Excision of the inguinal swellings performed and sent for histopathological examination, which revealed similar findings in all the three cases as bilateral testicular tissue with seminiferous tubules showing sparse spermatogonia with maturation upto only primary spermatogonia and interstitial leydig cell hyperplasia (Figure 5). Sertoli cells were unremarkable. Unremarkable epidydimis and spermatic cord were also noted. The final diagnosis in these three cases were made as androgen insensitivity syndrome with bilateral cryptorchid testis.

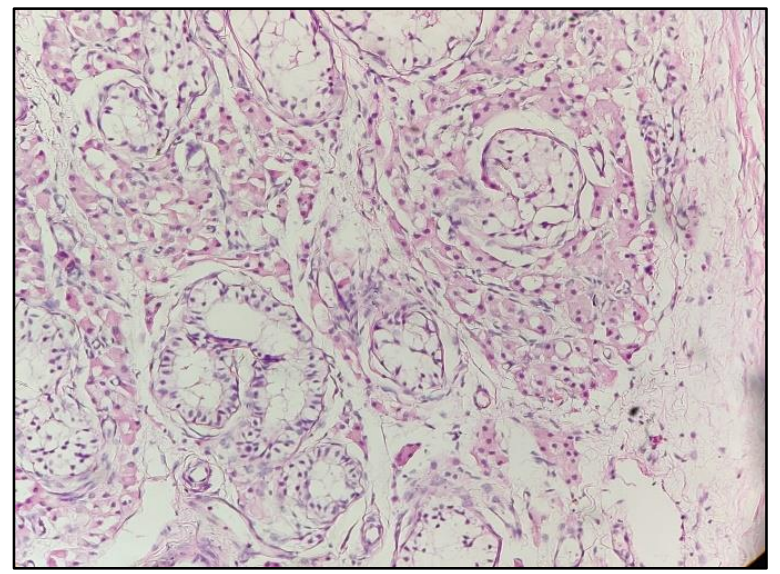

Figure 5: Seminiferous tubules lined by sertoli cells along with leydig cell hyperplasia in case of androgen insensitivity syndrome (H and E: 40x).

\section{Case 6}

Fourteen-year-old female child presented with primary amenorrhoea, delayed puberty and inadequate breast development. On physical examination patient had external ambiguous genitalia. On USG hypolastic uterus measuring $1.5 \times 0.6 \times 0.8 \mathrm{~cm}$ was noted. On karyotyping patient had chimeric DNA with 46XX $(60 \%)$ and 46XY (40\%) chromosomes. Bilateral gonadectomy along with hysterectomy was performed and on histopathological examination both the gonads revealed structures originating from Mullerian duct in the form of fallopian tube showing mucosa lined by columnar epithelium thrown into papillary folds along with muscularis propria and serosa. Also seen were Wolffian duct structures in the form of vas deferens. Sections also revealed ovarian stroma with rudimentary ovarian follicles and single 
small focus of calcification (Figure 6). There was no evidence of malignancy. The case was termed as mixed gonadal dysgenesis with rudimentary ovarian stroma and both Wolffian and Mullerian duct structures.

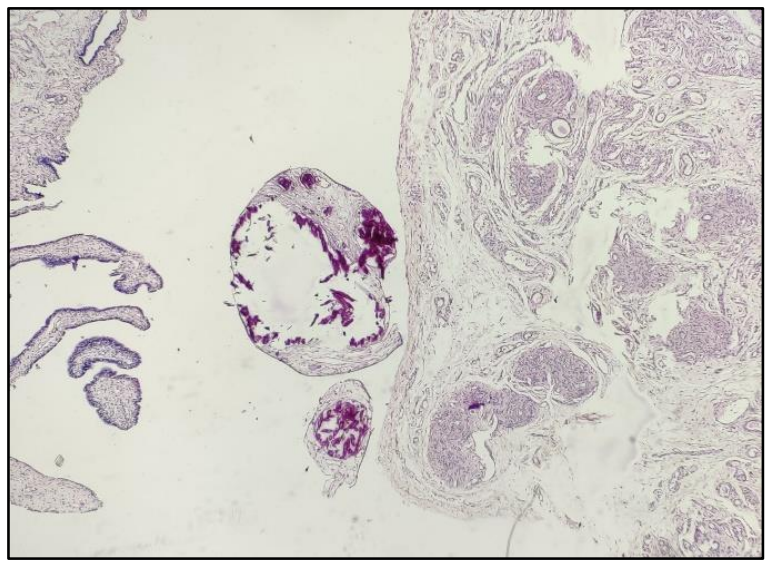

Figure 6: Ovarian tissue showing premature ovarian follicles without ovum along with single small foci of calcification and tissue from fallopian tube in case of mixed gonadal dysgenesis ( $\mathrm{H}$ and $\mathrm{E}$ : 20x).

\section{Case 7}

Sixty-nine-year-old female presented with abdominal pain. On history turned out to be a case of primary amenorrhoea and on further evaluation clinically she was labeled as a case of MRKH syndrome. On ultrasound examination patient was found to have agenesis of Mullerian duct and bilateral ovarian cysts. Patient underwent bilateral salpingo-oophorectomy and the gross specimen was received in this department (Figure 7). On histopathological examination left ovary showed simple serous cystadenoma (Figure 8) while right ovary revealed multiple follicular cysts (Figure 9) along with normal fallopian tube.

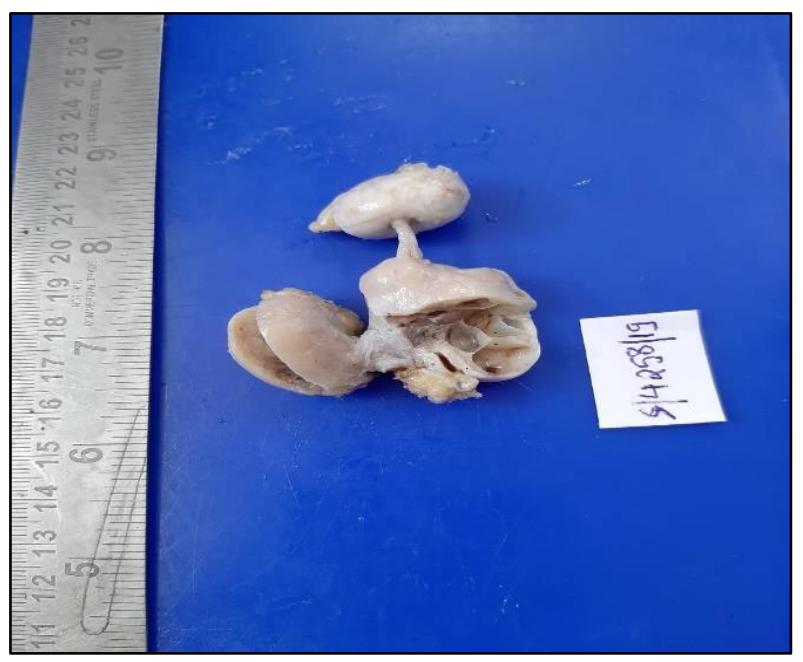

Figure 7: Gross-fixed specimen received in case of MRKH syndrome showing polycystic ovary along with a broad ligament fibroid.

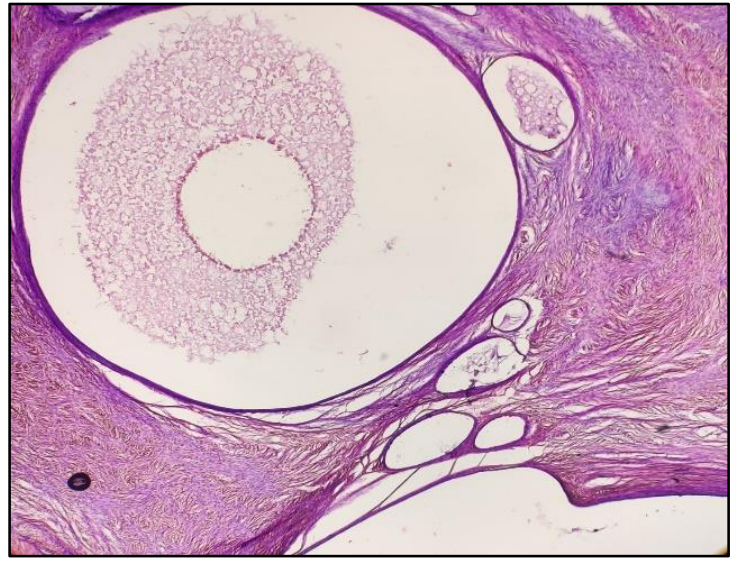

Figure 8: Simple serous cyst in case of MRKH syndrome, (H and E, 10x).

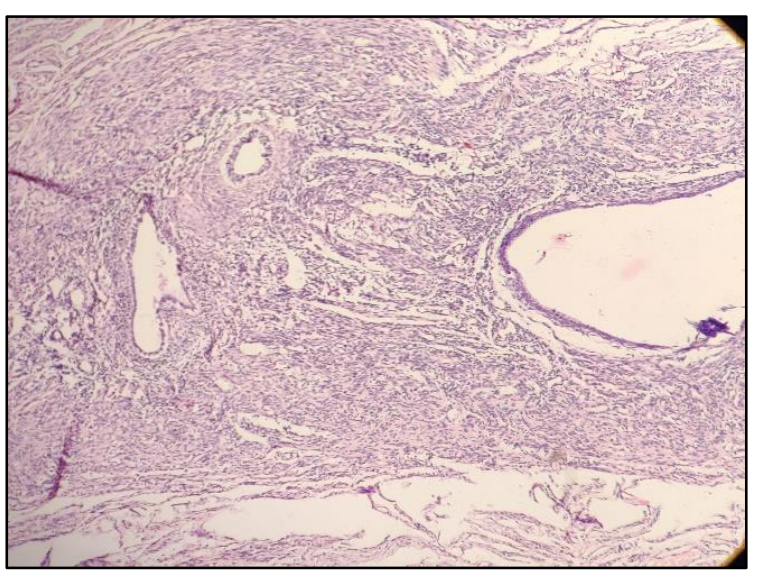

Figure 9: Premature ovarian follicles without ovum and ovarian stroma in case of MRKH syndrome (H and E: 40x).

\section{DISCUSSION}

The incidence of disorder of sexual development is 1 in 3,000 to $5,500 .^{1,2}$ which is very rare and prevalence of ovotestis is $1 / 20,000$ births again a very rare phenomenon.5,6 To the best of this knowledge till date only 500 cases worldwide have been reported of ovotestis. ${ }^{6}$ The common age group of presentation of DSD is in range of birth upto neonatal period. The cases which come to medical attention late in life include cases presenting with inguinal hernia in phenotypically female child and delayed puberty, primary amenorrhoea and virilisation. While phenotypically male child presents later in life with gross or cyclical haematuria and inappropriate breast enlargement at puberty. ${ }^{1,2}$ In the present case series the age range was one year to sixty nine year with majority of the patients presenting in range of eleven to fourteen year. According to literature congenital adrenal hyperplasia $(\mathrm{CAH})$ and mixed gonadal dysgenesis (MGD) contribute to approximately $50 \%$ of all cases of DSDs followed by androgen insensitivity syndrome (AIS). ${ }^{1,2,7,8}$ Mullerian agenesis also known as Mayer Rokitansky Kuster Hauser (MRKH) syndrome is a 
congenital malformation charcterised by failure of Mullerian duct to develop resulting in absence of uterus and hypoplasia of vagina. $^{9}$ In the present case series maximum were reported as AIS $(n=3)$, followed by ovotestis (true hermaphrodite) $(n=2)$ and one case $(n=1)$ each of MGD and MRKH syndrome. In the present series the most common presentation was ambiguous external genitalia at birth along with inguinal hernia, while case of true hermaphrodite presented as a male with cyclical haematuria and case of MRKH syndrome came to outpatient department with complains of abdominal pain and on further history revealed primary amenorrhoea. Most common karyotype in cases of DSD is $46 \mathrm{XX}$ though mosaicism is common. Translocation of gene for $\mathrm{HY}$ antigen from a $\mathrm{Y}$ chromosome to either $\mathrm{X}$ chromosome or autosome explains presence of testicular tissue in patient with 46XX karyotype. ${ }^{2,9,10}$ In the present series karyotyping was done in only four cases with two cases showing $46 \mathrm{XX}$ and two cases showing $46 \mathrm{XY}$ karyotype. On histopathological examination all cases were reported negative for malignancy. According to literature germ cell tumours have an increased incidence with increasing age in cases of AIS and all types have been reported. ${ }^{4,7-9}$

The frequency of malignant tumours was estimated at more than $30 \%$ by age 50 years. $^{4,8}$ Malignant germ cell tumours, including gonadoblastoma, a neoplasm composed of intimately admixed germ cells and sex cord cells in circumscribed nests with focal or diffuse calcification, occur in gonadal tissue in approximately $4 \%$ to $10 \%$ of cases. ${ }^{4,8}$ Brenner tumour, mucinous cystadenoma and endometriotic cysts have also been reported in ovarian tissue. Rugers and Scully indicated that tumours develop in $9 \%$ to $30 \%$ of patients with MGD and the commonest tumour reported is gonadoblastoma. Because of the risk of gonadal malignancies in these cases gonadectomy is being performed and extensive sampling and histopathological study is required to rule out one. Primary aim of treatment of DSD includes sex assignment surgery followed by plastic reconstructive surgery and hormonal therapy if required, but in cases of ovotestis and dysgenetic gonads early gonadectomy is required. ${ }^{11,12}$

A child born with ambiguous genitalia is more of a social emergency. Confirming a case of DSD and devising a management plan is one of the most challenging clinical condition for paediatric urologist. It requires a multidisciplinary approach and it is important to diagnose DSD correctly as soon as possible for assignment of gender and counseling of the patient as children with DSDs have the potential to become a well-adjusted functional member of the society. Laproscopic examination with bilateral deep longitudinal biopsies for histopathological evaluation is required which will further determine the presence of ovotestis, streak gonad, dysgenetic testis or malignancy in these cases and also confirm the diagnosis of DSD.

\section{ACKNOWLEDGEMENTS}

Authors would like to thank Department of Pathology, Grant Government Medical College and Government Hospital, Mumbai.

Funding: No funding sources

Conflict of interest: None declared

Ethical approval: Not required

\section{REFERENCES}

1. García-Acero M, Moreno O, Suárez F, Rojas A. Disorders of Sexual Development: Current Status and Progress in the Diagnostic Approach. Curr Urol. 2020;13(4):169-78.

2. Lee PA, Houk CP, Ahmed SF, Hughes IA. International Consensus Conference on Intersex organized by the Lawson Wilkins Pediatric Endocrine Society and the European Society for Paediatric Endocrinology. Consensus statement on management of intersex disorders. International Consensus Conference on Intersex. Pediatrics. 2006;118(2):e488-e500.

3. Sax L. How common is intersex? A response to AnneFausto Sterling. J Sex Res. 2002;39:174-8.

4. Thomas M. Ulbright and Daniel M. Berney, Testicular and paratesticular tumours, nonneoplastic diseases of the testis. In: Sternberg's, Stacey E, Mills, eds. Diagnostic Surgical Pathology. $5^{\text {th }}$ Edition. Philadelphia, Lippincott Williams and Wilkins; 2010: 1935-1940.

5. Matsui F, Shimada K, Matsumoto F, Itesako T, Nara $\mathrm{K}$, Ida S, Nakayama M. Long-term outcome of ovotesticular disorder of sex development: A single center experience. Int J Urol. 2011 Mar;18(3):231-6.

6. Ovotesticular Disorder of Sexual Development NORD (National Organisation for Rare Disorders). Available at: https://rarediseases.org/rarediseases/ovotesticular-disorder-of-sexdevelopment/.

7. Pang S, Wallace MA, Hofman L, Thuline HC, Dorche C, Lyon IC, et al. Worldwide experience in newborn screening for classical congenital adrenal hyperplasia due to 21-hydroxylase deficiency. Pediatrics. 1988 Jun 1;81(6):866-74.

8. Thyen U, Lanz K, Holterhus PM, Hiort O. Epidemiology and initial management of ambiguous genitalia at birth in Germany. Horm Res. 2006;66(4):195-203.

9. Watanabe K, Kobayashi Y, Banno K, Matoba Y, Kunitomi H, Nakamura K, et al. Recent advances in the molecular mechanisms of Mayer-Rokitansky-Küster-Hauser syndrome (Review) Corrigendum in/10.3892/br. 2017.1018. Biomedi Rep. 2017 Aug 1;7(2):123-7.

10. Cools M, Looijenga L. Update on the pathophysiology and risk factors for the development of malignant testicular germ cell 
tumors in complete androgen insensitivity syndrome. Sexual Develop. 2017;11(4):175-81.

11. Wünsch L, Holterhus PM, Wessel L, Hiort O. Patients with disorders of sex development (DSD) at risk of gonadal tumour development: management based on laparoscopic biopsy and molecular diagnosis. BJU Int. 2012 Dec;110(11c):E958-65.

12. Lee PA, Nordenström A, Houk CP, Ahmed SF, Auchus R, Baratz A, et al. Global disorders of sex development update since 2006: perceptions, approach and care. Hormone Res Paediatr. 2016;85(3):158-80.

Cite this article as: Bolde SA, Pirosha AA, Ramraje SN, Agale SV. Histopathological spectrum of disorders of sexual development: a case series of seven cases. Int J Res Med Sci 2020;8:2303-8. 